\title{
浅谈如何开展小学语文作文教学研究
}

付小红

重庆市万州区红光小学

DOI:10.32629/jief.v2i5.1388

[摘 要] 小学是语言学习的重要阶段, 优化教学策略, 提高语文教学质量, 让学生学好母语, 对学生今后学习生活具有重要的现实意义。写作 教学是语文教学的重要内容, 目前我国大部分小学都在改进语文写作教学, 在教学过程中发现小学生在写作时存在一些问题, 亟需广大教师认真 对待并对写作教学中出现的问题进行研究和分析, 并采取正确解决问题的方案, 帮助小学生提升写作能力, 从而促进学生的综合素质培养。

[关键词] 小学语文; 作文教学; 开展策略

中图分类号：G633.33 文献标识码：A

作文一直是语文教学的重难点, 由于写作要求学生有一定的字词储 备、语法基础、阅读积累、情感表达, 综合性强, 加之传统教学中缺乏 兴趣激发过程, 使小学作文教学处于 “读——抄——仿” 的模式中, 作 文学习中丰富的人文精神被无形瓦解, 导致学生写出来的作文千篇一律, 毫无真情实感。笔者结合自身多年实际教学经验, 就如何在小学语文教 学中做好写作教学工作并提升学生的写作能力提出自身的看法, 希望能 够给广大同仁起到一定程度的借鉴作用。

\section{1 做好写作氛围的营造工作}

良好的写作氛围可以给学生的写作学习起到一定程度的促进作用, 并 能够让学生在潜意识中形成正确的写作学习习惯。为了有效构建写作氛围, 教师要注重写作课堂上和学生之间的互动, 促使学生能够拉近和教师之间的 距离, 并在此基础上引导学生积极主动配合教师完成相应的教学任务, 从而 在提升教师教学效率和教学质量的同时, 获得自身学习效率和学习质量的明 显进步。除此以外, 教师还可以通过张贴优秀作文等方法, 让学生可以随时 随地欣赏优秀文章, 促使学生在潜移默化中提升自身的写作素养。

\section{2 培养学生留心观察生活的习惯}

为了促使学生的写作内容丰富而不空洞, 饱含情感而不泛泛而谈, 最高效的教学思路就是注重学生留心观察生活习惯的培养。这是因为写 作和学生的日常生活息息相关, 并且是取之于生活而为生活所服务的。 只有当学生有效养成留心观察生活的习惯之后, 学生的写作素材就能够 源源不断地积累, 并且能够在写作过程中以小见大, 以独特的视角阐述 平常的事件, 促使自身的写作质量获得进一步的提升。为了有效达到这 一教学目的, 教师可以首先培养学生写日记的习惯, 其次引导学生掌握 正确书写日记的技巧, 最后通过上述过程的努力引导, 学生无需教师任 务的指派就能够有意识地观察生活中的各类场景并产生自身的思考。

\section{3 培养想象力}

小学生写作普遍存在的现象是写作模式单一、内容空洞等, 沒有激 发学生丰富的想象力就无法拓宽学生的写作思路, 这是造成写作教学质 量低的主要原因之一。此外, 还有两方面的原因: 一方面是因为学生自 身生活阅历少, 能够如实写的素材有限, 另一方面学生的语言能力还未 培养完全, 不能运用语言顺利表达自己的想法和体会。因此, 语文教师 要积极采取有效的教学措施培养学生的想象力, 拓宽学生写作思路是唤 醒学生语言情感表达的对策。

丰富学生想象力有很多教学方法, 需要教师坚持不解并有耐心的实 施, 学生也要积极配合方能更高效地进行。例如在写作教学中可以运用 情境教学的方法, 让学生置身于任意情境中发挥自己的想象力, 情境教 学的形式有课文续写、语言游戏等。课文续写是在课堂学习的基础上, 对文章的情节进行联想和想象, 结合自己的思考进行的续写, 这可以帮 助学生更好地理解课文, 同时是提高写作想象力的有效途径。

\section{4 鼓励学生写随笔}

写作能力提高也是一个水磨工夫, 高质量的作文是建立在一词一字 的积累、一字一词的应用之上。故许多教师都要求学生写日记, 期望通 过长期短篇写作训练, 帮助实现写作能力的长足提高, 但由于日记形式 固定, 加之以往教学方式束缚, 导致许多学生写日记成了 “记流水账”, 仅存于形式, 不仅浪费了学生时间, 也无法取得预期教学效果。教师可 以通过鼓励学生写随笔, 破除形式限制, 以开放、自由的态度来鼓励学 生积累、创作。随笔可以是在阅读中摘抄的好词好句, 可以是仿写, 可 以是记录今天发生的一件小事, 甚至是自己写的一首小诗, 只要学生在 写随笔过程中用心即可。笔者在教学中便是如此, 每两周便抽出一节课 来检查学生的随笔, 并让学生向大家分享为什么写这些。如此一来学生 便能自由发挥, 每个学生都能从中获得感悟, 学生写作水平也就在日积 月累中获得提高。

\section{5 让学生互批文章}

闭门造车无法取得任何进步, 只有学生踊跃交流学习心得、写作心 得, 才能相互竞争、相互借鉴、共同进步。但单纯地交流课不能很好地 激发学生学习兴趣, 在课堂上让个别学生朗读自己写的文章也不能兼顾 所有学生, 故教师可以采取另一种办法, 让学生互批文章, 让学生以教 师的角度批阅文章, 并给出中肯的评价。例如笔者在某一堂写作课上, 先将收上来的作文随机发给学生, 并指导学生如何批阅, 为避免学生出 现攀比或相互 “放水”, 在作文互批过程中笔者没有要求学生给分数或等 级, 只要求学生对写的好的部分分析哪里好, 对欠缺部分提出适当改善 意见。在学生批改完后, 笔者随机抽选几篇文章, 再加以细致分析讲解, 对文章水平高、批阅恰当的学生提出表扬, 对批阅存在瑕疪、文章有待 进步的学生给予鼓励与针对性意见, 以此帮助学生提高自身写作水平。 通过这样的方式, 让学生相互学习、相互借鉴, 找到自己与其他学生之 间的差距, 促使学生更好地学习语文、学习写作。

\section{6 结语}

加强写作教学对于提高学生语文水平有至关重要的作用, 写作过程 可以锻炼学生的文字应用能力和想象力, 写作过程中学生逐步学会思考 从而建立正确的人生观、价值观和世界观, 对于小学生健康全面的成长 有积极的促进作用。因此, 重视写作教学并积极改进是所有语文教师的 重任, 正视写作教学中存在的问题并采取有效解决方法, 着力提高学生 写作水平, 以加强学生的语文能力。

\section{[参考文献]}

[1]王林.线谈如何优化小学作文教学[J].新课程,2020(34):49.

[2]沈静. 以趣激情 乐于作文[J].作家天地,2020(16):67+69.

[3] 金珂. 基于多媒体教学的小学作文教学 [J]. 试题与研 究,2020(24):13. 